\title{
Recent Advances of DC Bus Systems for Electrical Ships and Analysis of a Real Case
}

\author{
Guomei Chang, Yunxiang Wu, Shiyi Shao, Zhaoxia Huang, Teng Long
}

\section{Introduction}

\subsection{Background and motivation}

The maritime industry accounts for a significant share of global emissions of $\mathrm{CO} 2$, nitrogen oxides (NOx), and sulphur oxides (SOx), giving it a substantial environmental footprint. According to the research conducted by the Lloyds Register and University College London (UCL) on Global Marine Fuel Trends 2030 , if no actions are taken, exhaust gas emissions from shipping will double by 2030 and remain on an upwards trajectory. Ships also contribute to local problems of poor air quality, constituting a significant threat to global health. Through chemical reactions in the air, NOx and SOx are converted into fine particles of sulphate and nitrate aerosols.

To tackle emission issues, international organisations and regional government start introducing regulations and schemes. For reducing $\mathrm{CO}_{2}$, the International Maritime Organisation (IMO) adopted the so-called Greenhouse Gas (GHG) initial strategy in 2018, envisaging a reduction in the total GHG emission from global shipping by at least $50 \%$ by 2050 compared to 2008 . The European Union (EU) has introduced the shipping monitoring, reporting and verification (MRV) regulation, which is designed to gather data on $\mathrm{CO}_{2}$ emissions based on ships' fuel consumption. Furthermore, the EU has introduced the European Green Deal to put Europe on track of zero GHG emission by 2050. In terms of reducing SOx and NOx, the $0.5 \%$ global sulphur limit of maritime transport came into effect from 1 January 2020. The Emission Control Areas (ECAs), namely, the Baltic Sea, North Sea, North American and US Caribbean have also deployed additional control of SOx and NOx emission. China has also established the ship-generated air pollutant emission control areas and issued regulations to reduce the emission of ship-generated air pollutants such as SOx, NOx, particulate matters and volatile organic compounds etc. The UK government has introduced the Clean Maritime Plan, requiring all new and commercial vessels in UK waters are zero emission by 2025.

Restrictions imposed on ship-owners force them to invest in technologies on cutting emission. Removal of SOx and of NOx from exhausts requires significant alterations on-board, including additional tanks, pipes, pumps, water treatment systems and storage of chemicals and special waste to be disposed at 
dedicated facilities. Scrubbers removing sulphur from the engine exhaust increase the power consumption, thereby increasing emission of $\mathrm{CO}_{2}$.

Instead, the Integrated Electric Propulsion (IEP) systems has become a more welcomed and beneficial approach to reduce emission due to its clear economic benefits in fuel saving. The IEP systems have made successful records, including the large cruise liner (Queen Elizabeth) to smaller ferries, and the large navy ship (the Type 45 destroyers from the UK's Royal Navy) to smaller oil-platform supply vessels.

The propulsion thruster in IEP systems is provided by electric motors which are more efficient than internal combustion engines (IEC) particularly at low speed operations. In addition, bulky and heavy gearbox and clutch used in IEC propulsion are eliminated. Continuous development and advancement of power electronics based motor drives have enabled high dynamic performance and controllability of propulsion thrusters. The mechanical transmission of energy is replaced by electrical transmission, offering more flexibilities in ship compartment design because the rigid propeller shafts are replaced by flexible electric cables. The average fuel saving of the full IEP system is more than $30 \%$ of the IEC counterpart for the same ship and mission profile. This incentive of fuel saving in conjunction with smaller footprint and weight of the entire system is convincing for ship owners to electrify their fleets. As a consequence, emissions have been reduced too.

To date, the IEP systems for ships are dominated by the AC Bus system where the common connecting point is at fixed frequency (60 or $50 \mathrm{~Hz}$ ) and fixed voltage. The AC Bus is formed by ferromagnetic components such as transformers, line reactors and circuit breakers in the AC switchboard and only the conventional analogue control can be applied. The switch-mode power conversion (digital control) only control the propulsion drives and the AC Bus is controlled in analogue means due to its ferromagnetic nature. All Diesel Generators (DGs) are directly connected to the AC Bus and have to be synchronised, which limited the controllability and adaptability of the entire IEP system.

In contrast, the DC Bus system is naturally simpler than the AC Bus system thanks to the absence of frequency, phase angle and reactive power. The entire DC Bus is fed by power electronics based converters, requiring all on board loads and supplies, from the DGs to propulsion to hotel loads, to be independently controlled by using power electronics based converters. Therefore, the DC Bus system is a high semiconductor power system which can be entirely controlled by digital means. 
In this article, the typical DC Bus system for full IEP of ships is introduced. Modular power electronics based power converters used in DC Bus systems are described, including the converter for the hotel loads and its special fault ride-through ability. Advantages of the DC Bus system has been partly validated by a real case, the Shen Kuo research vessel (2,100-ton dead weight tonnage). Benefits of using the DC Bus validated by a mission from Hainan, China to Mariana Trench are presented in this article.

\subsection{Conventional AC Power systems for ships}

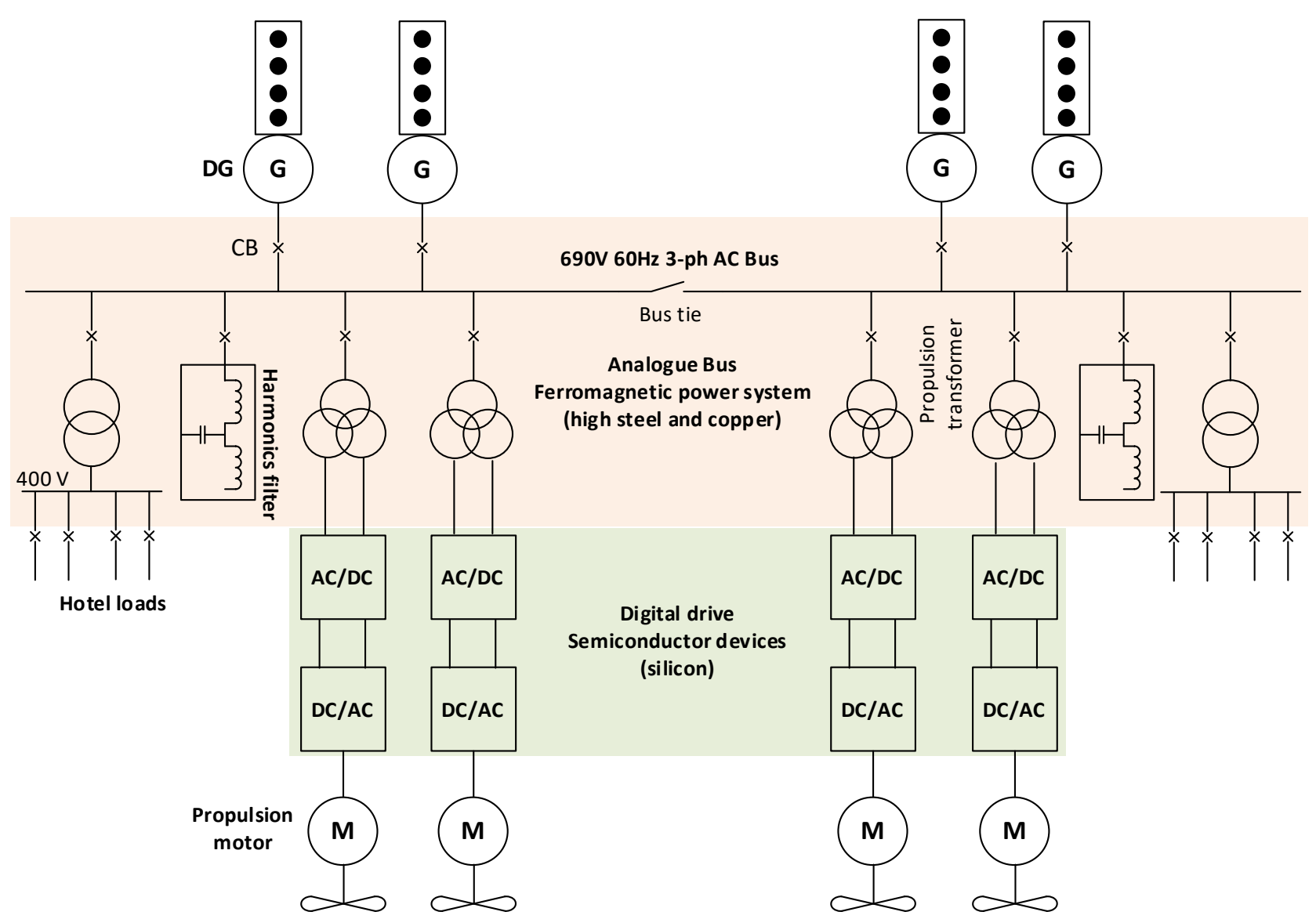

Figure 1 AC Bus Integrated Electric Propulsion (IEP) system schematics, using more steel and copper for ferromagnetic components. Control of AC Bus and hotel loads is analogue.

Conventional AC Bus system shown in Figure 1. The shipboard electricity is generated by diesel generators (DGs) each consisting of an AC generator coupled with a diesel engine as the prime mover. All DGs are directly connected to the AC Bus thus all generators need to be strictly synchronised. The hotel loads are also synchronised with the DGs too due to direct connection.

The propulsion drives in the AC Bus IEP systems are equipped with power electronics based converters which can be digitally controlled. The drive comprises AC-DC and DC-AC converters to convert fixed frequency and voltage $A C$ power to variable frequency and variable voltage AC power for speed and 
torque control of the propulsion motors. The Diode Front End (DFE) consisting of a large transformer and diode bridge are commonly adopted as the AC-DC rectifier for propulsion drives. However, the uncontrollable DFE produces large current harmonics thus dedicated harmonic filters where larger line reactors and a number of capacitor are incorporated for meeting the grid code because the hotel loads are fed by the AC Bus directly.

\section{DC Bus system architecture}

\subsection{System schematic}

The schematic of the DC Bus IEP system is shown in Figure 2. The AC power generated by the DG is immediately rectified into DC power for the DC Bus. The Bus voltage is controlled by the power electronic based AC-DC rectifiers at the DG side.

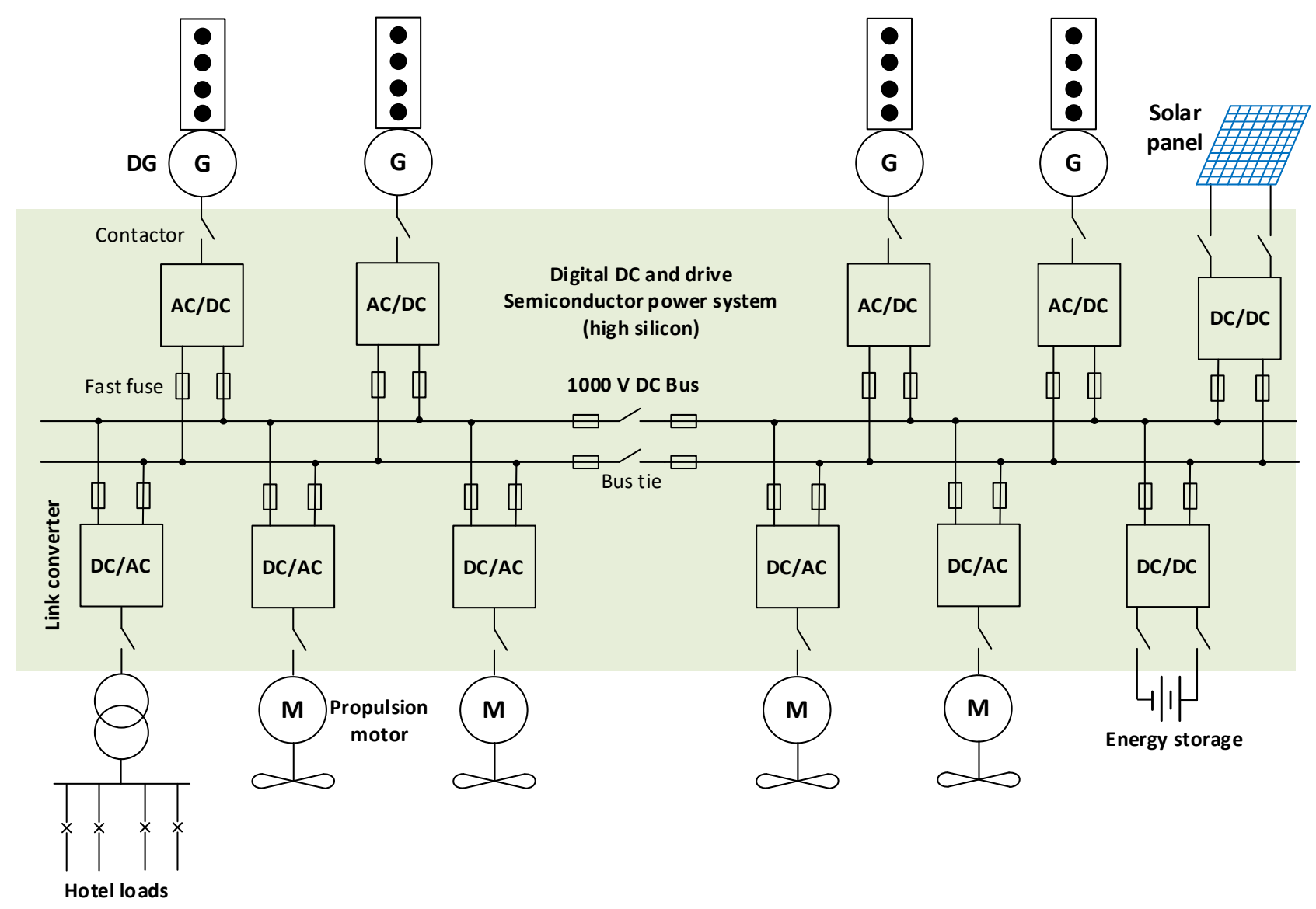

Figure 2 DC Bus Integrated Electric Propulsion (IEP) system schematic, using more silicon for semiconductor devices. Both the Bus, propulsion drives and hotel loads are digital.

All loads need to be connected to the DC Bus via a converter. For AC drives, only DC-AC inverters are employed to convert the Bus DC voltage to variable voltage and variable frequency AC voltage to control 
the electric motors. The hotel loads of the DC system are fed by DC-AC inverters in accordance with an isolation transformer for fixed voltage and fixed frequency AC supplies. The isolation transformer is much smaller than transformers used in AC Bus systems as only a fraction of Bus power used by hotel loads.

The DC Bus system significantly reduces the complexity of the IEP system because the essential intermediate DC voltage of each AC drives are unified and connected as the common DC Bus therefore the large and costly rectifying transformer and AC-DC rectifier at each drive are eliminated. The absence of frequency and phase angle of DC Bus enables fast interconnection of DGs and AC drives for a more flexible and configurable system.

The DC Bus IEP system is a high semiconductor power system using more silicon to replace steel and copper in the AC Bus system. In contrast to the AC Bus IEP system, power at the DC Bus is entirely generated and consumed by power electronic converters and each supply and consumption unit can be independently controlled. The modular and granular control at converters unlock full potentials configuration and operation of the DC Bus, i.e. more flexibilities of interconnecting of loads or supplies to the DC Bus for maximising system level efficiency and reliability, which also enables high penetration of new energy storage and sources such as shipboard batteries and solar power generation directly to the DC Bus. The power electronic converters have higher power density compared to the ferromagnetic devices. The cost of power electronic converters is destined to decrease because the rapid cost down of power semiconductor manufacturing process and the low cost and large reserves of the raw material, silicon.

\subsection{Power conversion converters in DC systems}

\section{A. Modularity and scalability of converters in DC Bus IEP systems}

To streamline the design and implementation of increased number of converters used in DC Bus systems, a versatile building block by using the common power electronic circuit can be used in both AC-DC and DC-DC conversion as shown in Figure 3. This modular design is becoming popular in both DC Bus IEP systems to reduce both capital and maintenance costs. The power modules can be connected in parallel as multiple channels for higher power ratings. The common building block of power electronic circuit can also be housed by standardised converter cubicles which are located adjacent to each other, thus the physical length of the DC Bus linking those converters can be reduced so does miscellaneous manifolds. 
The high modularity and scalability of the power conversion converters for DC Bus systems offers costeffective solutions for a variety of ships.
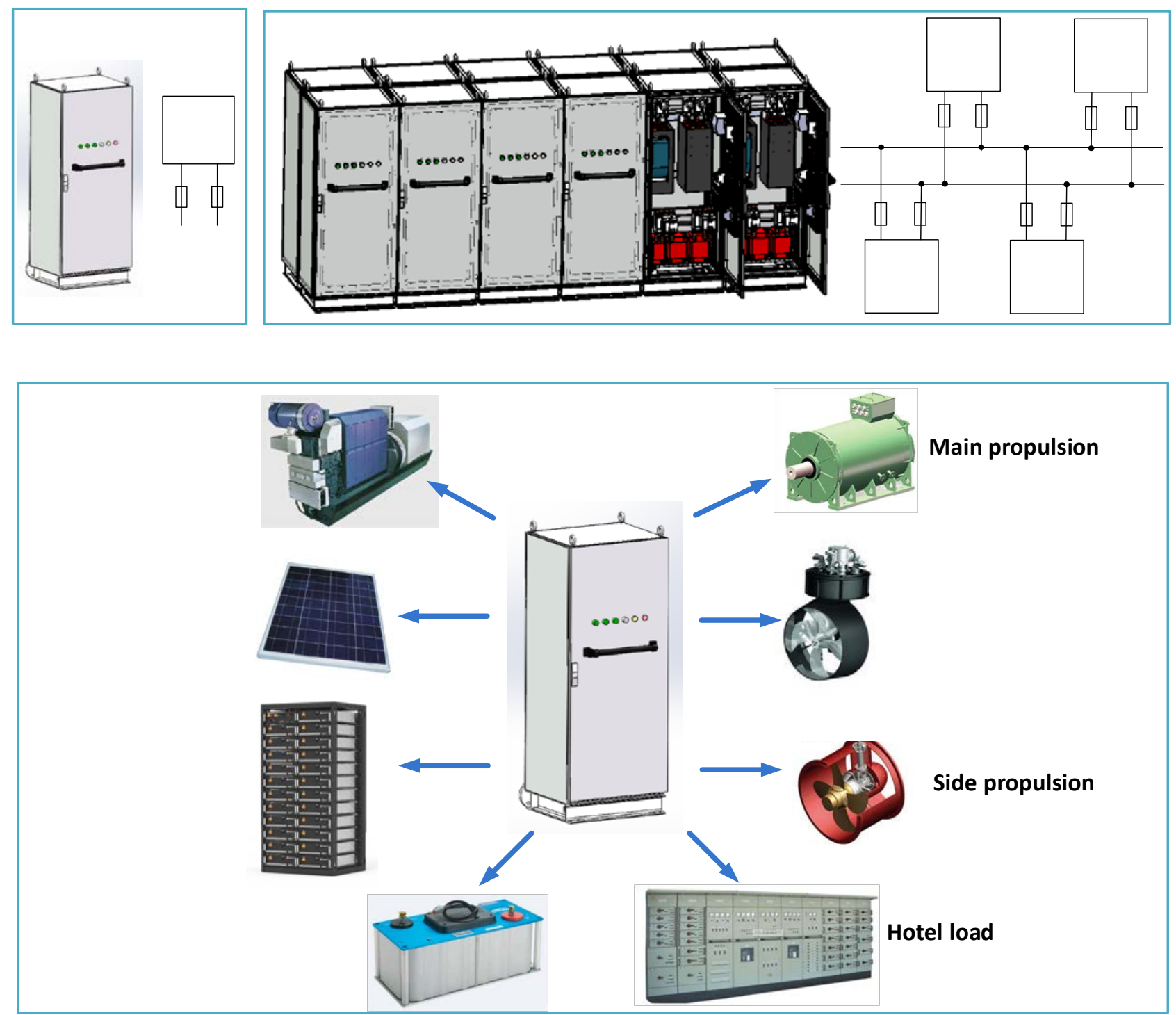

Figure 3 High modularity, adaptability and scalability of power electronics based converters for DC Bus systems

B. Hotel load supply converter short circuit fault ride-through

The DC Bus IEP system needs DC-AC converters to provide fixed voltage fixed frequency AC power from the DC Bus to the hotel loads such as lighting, air conditioning and other on board loads. The hotel load supply converter needs to have fault-ride through abilities. As shown in Figure 4, the low voltage AC Bus feeds hotel loads via miniature circuit breakers (MCBs). When a short-circuit fault occurs at one of loads, its MCB needs a short period of time, normally tens of milliseconds to disconnect the faulty load. 
However, the conventional power electronic converter trips within one millisecond to protect the power semiconductors from the fault current. In order to have fault discrimination, the hotel load supply converter must provide the fault current for an adequate period time to allow the MCB to disconnect the faulty load without undermining the power electronic devices of the converter.

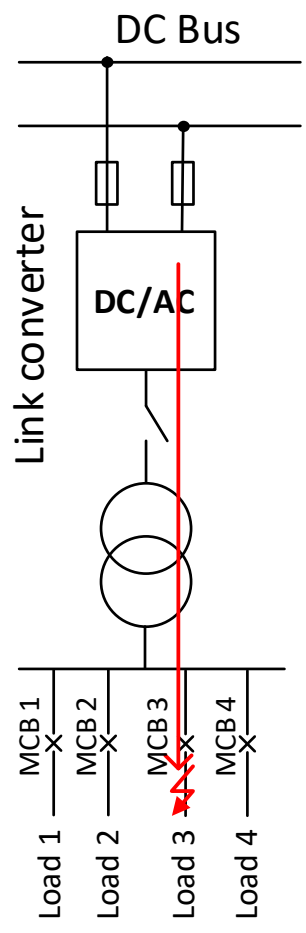

(a)
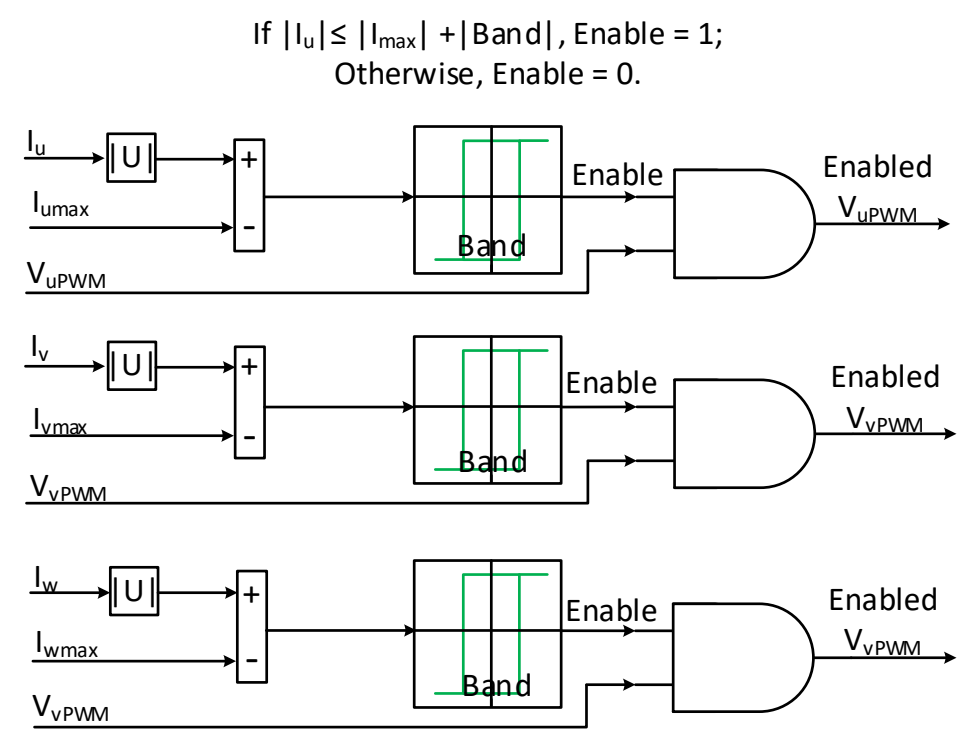

(b)
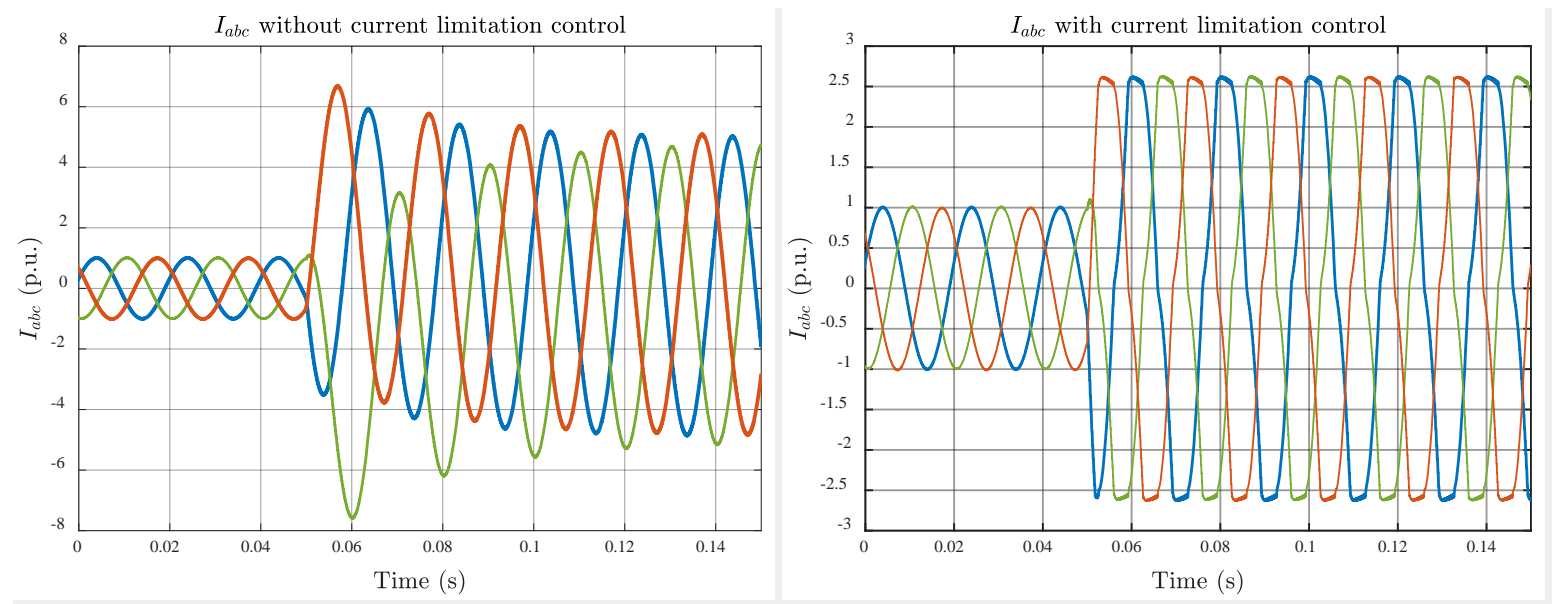

(c)

Figure 4 Link converters short circuit fault ride-through function. (a): discrimination of MCB 3 for faulty hotel load 3; (b): current limitation control logic; (c): comparison of fault current occurring at 0.05 s. Without current limitation control, fault current reaches to 7 p.u. and has a large asymmetry. With current limitation control, fault current is controlled to 2.5 p.u. which is adequate for MCB disconnection. 
A current-clamping technique as shown in Figure 4 (b) can be adopted for the hotel load supply converter to provide a clamped fault current for a limited time to enable MCB disconnecting the faulty load. Meanwhile, the clamping value and duration are carefully set by the bandwidth of the hysteresis controller in Figure 4 (b) in order to ensure the power semiconductors in converter are still within their Safe Operating Areas (SOAs). The clamped current will inevitably cause under voltage at the low voltage AC Bus of the hotel loads during the fault clearance interval. The short circuit fault discrimination and clearance is prioritised and the under voltage trip should not override the short circuit fault clearance. Therefore, the under voltage protection threshold needs to be lifted or modified when the hotel load supply converter engages the short circuit fault ride-through procedure.

\subsection{Connection to new energy storage and sources}

The DC Bus offers friendly interconnection to DC supplies and loads because only DC-DC converters are required rather than $D C-D C$ and $D C-A C$ converters for the $A C$ Bus system as shown in Figure 3. This technological advancement is starting showing merits for increasing deployment of on-board solid-state energy storages such as batteries and super capacitors for meeting demands of higher efficiency and lower emission. In the future, other DC loads such as electronic equipment and DC supplies such as solar power generation can be directly fed to the DC Bus. The direct DC-fed network for electronic loads improve Uninterrupted Power Supply (UPS) response time and increase system level reliability and efficiency, which has been successfully pioneered in other emerging applications such as datacentre power supplies.

\section{AC Bus DC load/supply connection}

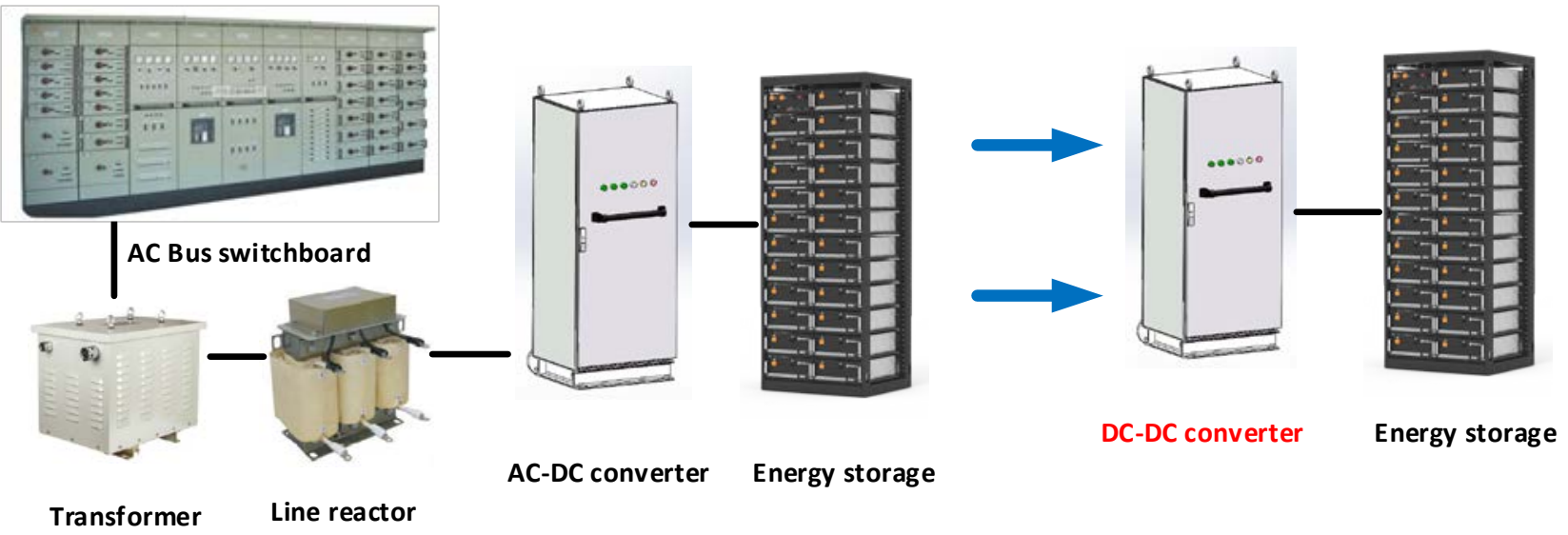




\subsection{Protection}

Due to lower system impedance from the absence of transformers and generator impedance at the DC Bus, short circuit fault current in the DC Bus system has a much higher increase rate than the AC system. Power converters are prone to overcurrent for even very short time because the silicon based power electronic devices exhibits much smaller thermal time constant and more sensitivity to over temperature so the converter needs to be cut off before the fault current reaches to the very high value. The fast increase rate of $D C$ fault current requires the fault protection mechanism to complete disconnection much faster than the $A C$ counterpart. The absence of natural zero cross of the $D C$ current introduces more challenges to disconnecting the fault current than the $\mathrm{AC}$ counterpart because the arc from breaking a DC current is difficult to be supressed and contained.

Instead of using circuit breakers (CBs), the state-of-the-art solution of breaking DC short circuit fault current is to use ultrafast fuse (as known as the power electronic fuse) which can disconnect a faulty circuit between 300 to $600 \mu$ s subject to the fault current value. Fast fuses are connected at the DC terminals of any converters and Bus tie connected to the DC Bus as shown in Figure 2. The ultrafast fuse is a sacrifice solution and the fuse must be replaced once protection occurs, meaning longer down time than CBs is inevitable after a fault due to fuse replacement.

To have a quicker recovery time from fault, reusable and automatic solid-state switches (SSS) is an emerging and high performance solution. The SSS incorporates power electronic devices and conventional motorised CBs or only power electronic devices. The SSS is able to disconnect fault current between 10 to $100 \mu$ s and the feeder can be immediately reconnected after tripping. To date, the SSS is still at high prices, for example a 1 kA SSS costs more than 3000 Euro, which is 10 times of the ultrafast fuse. The sensible solution is to have both fast fuse and SSS in the system, depending on the power security level of the load. A system level tripping and load prioritisation schedule needs to be designed for the DC Bus system consisting both fast fuses and SSS.

\section{Control and operational management}

\subsection{Variable speed DG operation}

The DG is more efficient and having less emission when operating when the load and rotating speed of the DG are in positive correlation, i.e. high speed for heavy loads and low speed for light loads. However, for the AC Bus system, the diesel engine has to be operated at the fixed speed to ensure the fixed 
frequency output of the directly coupled generator. For the DC Bus system, the DC Bus voltage can be regulated at the fixed voltage at nearly all DG speeds. This decoupled controllability allows operation optimisation of the DG in accordance with various loads for fuel saving and emission reduction.

Operations such as start-up, docking, manoeuvring and dynamic positioning (DP) are typical light loads and consume more fuel thus more emissions. The ship operators intend to operate less DGs and each is at higher loads than more DGs and each at light loads. At light loads, lower rotating speed of the diesel engine can further reduce fuel consumption and emission than higher speed.

The specific fuel oil consumption (SFOC) of a typical 4.3 MW DG is shown in Figure 6. For a 50\% load, operating 1-off DG at $50 \%$ is more efficient than 2-off DGs and each operates at $25 \%$ load. In addition, it is evidenced that the DG is more efficient at low speed when the load is light. As shown in Figure 6, the DC Bus IEP system enables 1-off DG at $75 \%$ speed for $50 \%$ load, which is $4.7 \%$ fuel saving than 1-off DG at $100 \%$ speed and $50 \%$ load, and $14.3 \%$ fuel saving than 2-off DGs at $100 \%$ speed $25 \%$ load each.

\section{Typical diesel SFOC}

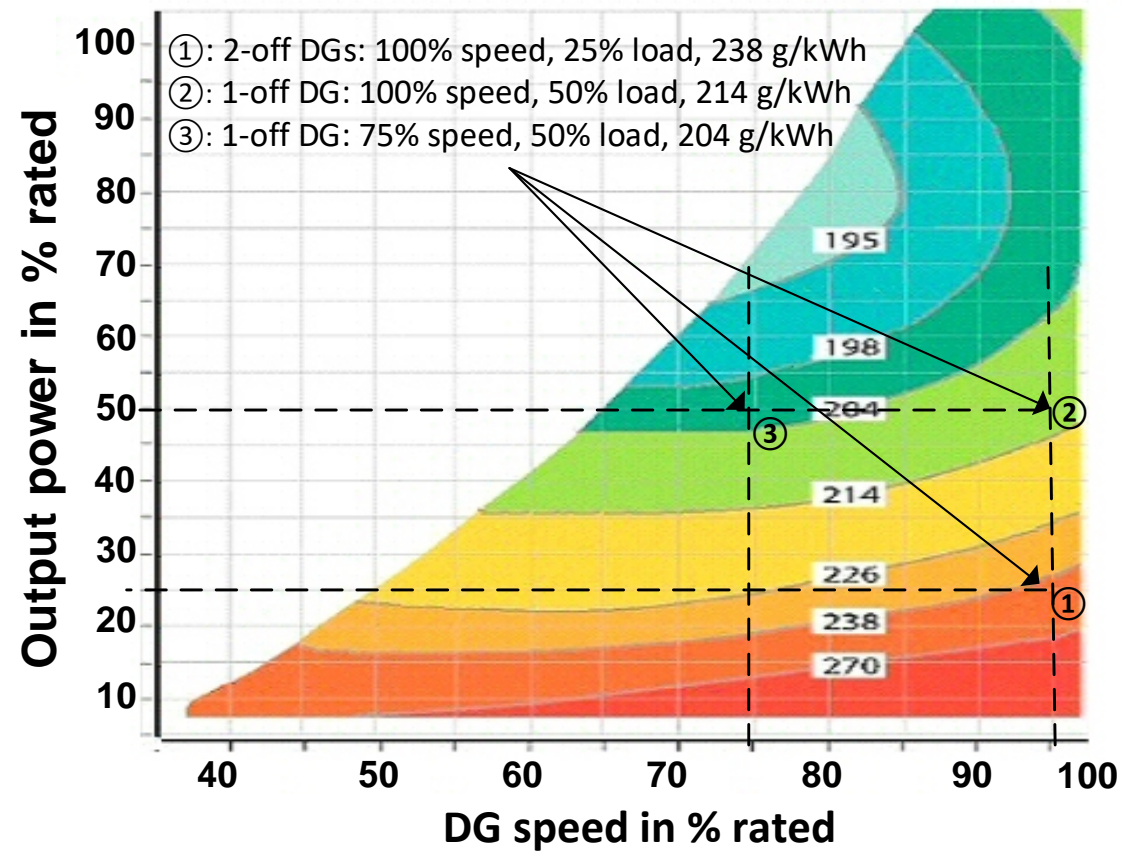

Figure 6 Specific fuel oil consumption (SFOC) map of a 4.3 MW DG. Colour shades are fuel consumption in $\mathrm{g} / \mathrm{kWh}$.

\subsection{Transient operation}

The transition time for a DG from galvanic disconnection to connection to the Bus is an important requirement for maritime IEP systems. In order to save fuel, vessel operators intend to keep the minimum 
number of DG online, i.e. connected to the Bus, provided that mandatory requirements from classes are met. If any fault or tripping occurs at a live DG, at least one spared DG must be connected to the Bus and provide power as soon as possible.

Typical transition time of a 1.1 MW DG for $690 \mathrm{~V}$ AC Bus IEP system is 40 seconds because the DG needs to ramp up to accelerate to the rated speed then adjust its output voltage phase angle and voltage to synchronise the AC Bus as shown in Figure 7.

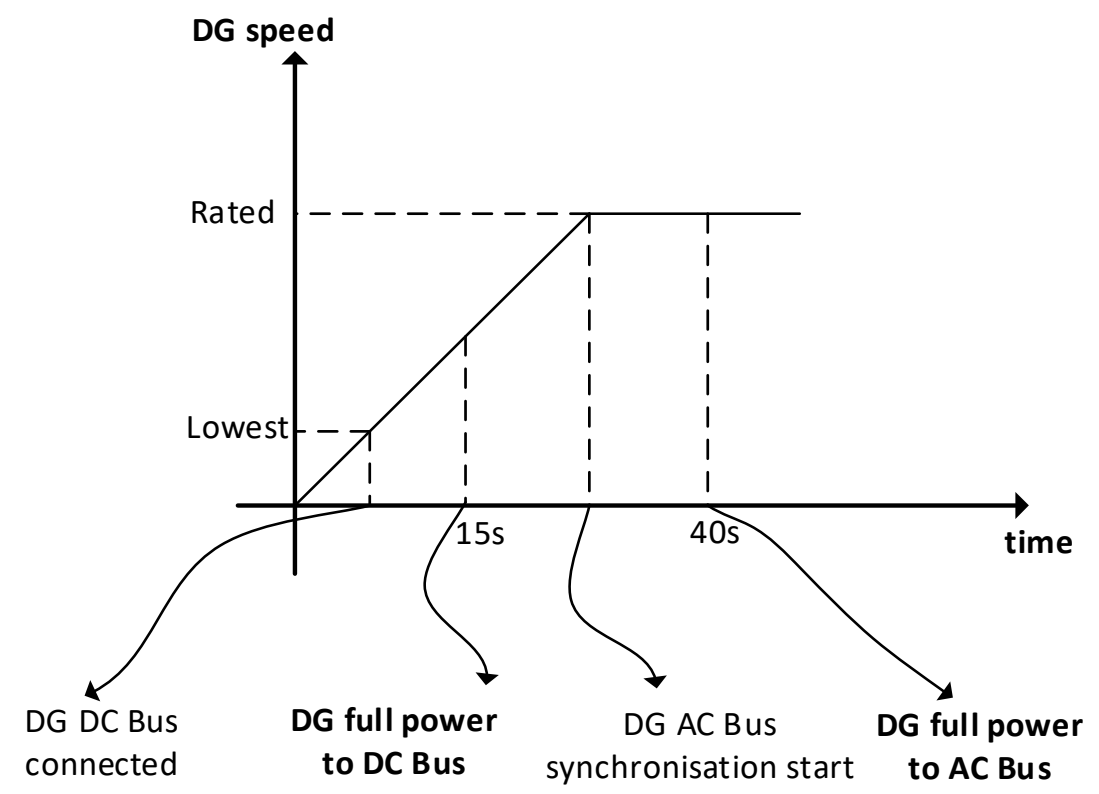

Figure $7 D G$ connection schedule of DC Bus and AC Bus systems.

For DC Bus systems, DG connection procedure is significantly simplified so the transition time is largely reduced. First, neither frequency nor phase angle needs to be synchronised in the DC system. The DG is ready to be connected when the output voltage of the DG AFE is controlled to the DC Bus. Second, the AFE is able to control its output voltage to the DC Bus when the DG is at low as shown in Figure 7. For a $1 \mathrm{MW}$ DG, less than 15 seconds are required to achieve $1 \mathrm{kV}$ output DC voltage for connecting the DC Bus. The merit of shorter transition time of DGs makes the DC Bus system more reliable and resilient than AC Bus IEP systems, allowing the ship operators more flexibilities and configuration options to reduce fuel consumption and emission. 


\section{Advantages in a real application}

\subsection{Hardware and structure}

The first double-body research vessel, Shen Kuo, using DC Bus IEP system is built by Taihe Ocean Technology Group Ltd as shown in Figure 8. The DC Bus IEP system of Shen Kuo incorporates two DC Buses, Port side and Starboard side which can be inter-linked by the DC Bus tie. Each DC bus is fed by one 1.1 MW DG and one $400 \mathrm{~kW}$ DG combined with their AC-DC rectifiers to feed the $1 \mathrm{kV}$ DC Bus. Two $1 \mathrm{MW}$ main propulsion drives and one $300 \mathrm{~kW}$ side propulsion drive are the main loads. The hotel loads are fed by DC Buses via two DC-AC supply converters. The single line schematic of the DC Bus IEP system of Shen Kuo research vessel is shown in Figure 9. The DC Bus IEP system is designed and manufactured by the Wuxi Silent Electric Ship Technology Ltd (SES Tech).

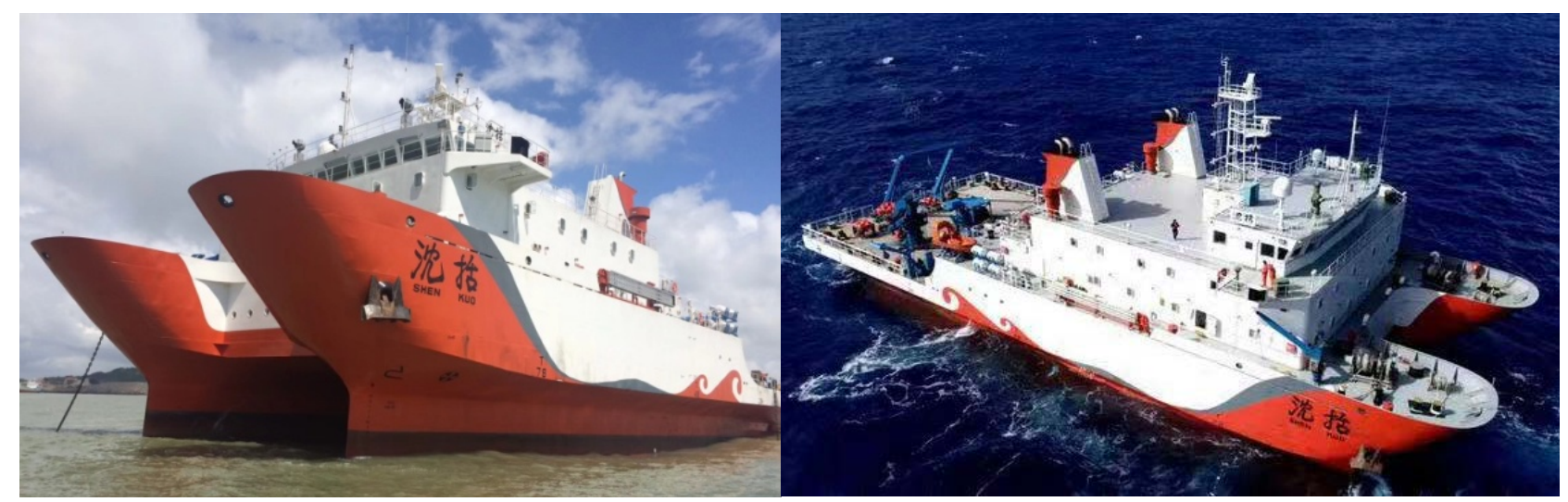

Figure 8 Shen Kuo research vessel, 2,100 ton placement, 63 meter long, 23 meter wide, CCS certified, built in 2018

Each building block of the converter used in the DC Bus system is formed by a three-phase full bridge module using $1.7 \mathrm{kV}$ IGBTS and film capacitors. The building block is water cooled and rated at $800 \mathrm{~kW}$. For DG rectifiers and main propulsion drives, two building blocks are directly connected in parallel.

The entire DC Bus system for Shen Kuo is compact. As shown in Table 1, the DC Bus IEP system occupies $13.4 \mathrm{~m}^{2}$ and weighs 10.1 ton, offering a $41 \%$ and $56 \%$ reduction of footprint and weight respectively over the $A C$ counterpart for the same purpose. The footprint reduction is mainly due to the absence of the AC switchboard and the rectifying transformers. The considerably smaller footprint and weight benefit the ship owner with more space and payloads. Not only are the footprint and weight reduced but also the cabling and manifolds therefore installation and maintenance become simpler. System simplification and footprint reduction is illustrated in Figure 10. 
The cost of the DC Bus IEP system is also compared with the AC counterpart for the same system specification of the Shen Kuo vessel as shown in Table 1. Albeit saving from switchboard and propulsion transformers, the overall cost of the DC Bus system is modestly higher, which is attributed to more power electronic devices used in forming the high semiconductor DC Bus system. However, it is expected that the DC Bus system will become more cost-effective in the future as a result of continuous cost down of power semiconductors and more uptakes of DC Bus systems in applications.

Table 1 Space, weight and cost comparison between DC Bus and AC Bus IEPs for Shen Kuo research vessel

\begin{tabular}{|c|c|c|c|c|c|c|}
\hline & \multicolumn{3}{|c|}{ AC Bus IEP system (1) } & \multicolumn{3}{|c|}{ DC Bus IEP system } \\
\hline & Footprint & Mass & $\operatorname{Cost}^{(2)}$ & Footprint & Mass & $\operatorname{Cost}^{(2)}$ \\
\hline Switchboard & $8 \mathrm{~m}^{2}$ & $6 \mathrm{t}$ & USD 160k & $\mathrm{N} / \mathrm{A}$ & N/A & N/A \\
\hline Power converter (3) & $5.4 \mathrm{~m}^{2}$ & $3 t$ & USD $690 \mathrm{k}$ & $11.4 \mathrm{~m}^{2}$ & $7.6 \mathrm{t}$ & USD 990k \\
\hline Main Propulsion transformer (4) & $6.5 \mathrm{~m}^{2}$ & $9.2 \mathrm{t}$ & USD 85k & N/A & $\mathrm{N} / \mathrm{A}$ & N/A \\
\hline Side Propulsion transformer (5) & $1 \mathrm{~m}^{2}$ & $1.2 \mathrm{t}$ & USD $14 \mathrm{k}$ & N/A & N/A & N/A \\
\hline Ship network transformer (6) & $2 \mathrm{~m}^{2}$ & $2.5 \mathrm{t}$ & USD 20k & $2 \mathrm{~m}^{2}$ & $2.5 \mathrm{t}$ & USD 20k \\
\hline Total & $22.9 \mathrm{~m}^{2}$ & $21.9 \mathrm{t}$ & USD 969k & $13.4 \mathrm{~m}^{2}$ & $10.1 \mathrm{t}$ & USD $1.01 \mathrm{M}$ \\
\hline
\end{tabular}

Note: (1): Comparison of electric machines (motors and generators) is neglected due to the same electric machines used in both the AC and DC Bus systems. (2): The cost figures are estimated and transferred from RMB to the US Dollars at the rate of $1 \mathrm{RMB}=0.14$ USD. (3): For AC Bus: 2-off $1 \mathrm{MW}$ AC-DC-AC drives and 1-off 300kW AC-DC-AC drive; For DC Bus: 2-off $1.1 \mathrm{MW}$ AC-DC rectifiers, 2-off $400 \mathrm{~kW}$ ACDC rectifiers, 2-off $1 \mathrm{MW}$ DC-AC inverters, 1-off 300kW DC-AC inverter, 2-off AC-DC-AC 630kVA hotel load converters. (4): 2-off $1 \mathrm{MW}$ transformers for AC Bus system only. (5): 1-off $300 \mathrm{~kW}$ transformer for AC Bus system only. (6) Each AC Bus and DC Bus system has 2-off 690 kVA transformers. 


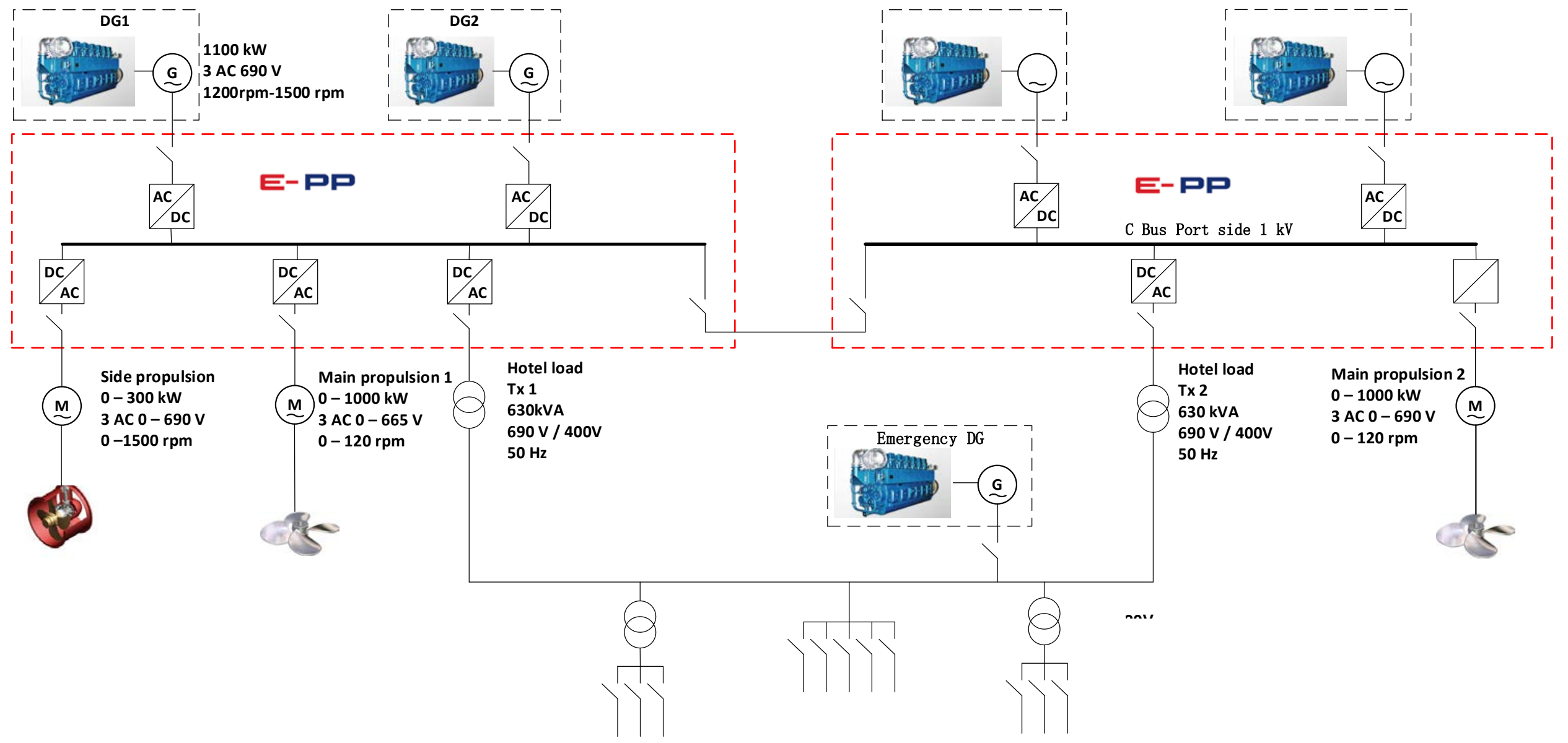

Figure 9 Single line schematic of DC Bus system of Shen Kuo research vessel (2,100 ton). Courtesy to Wuxi Silent Electric Ship Technology Ltd (SES Tech). 
AC Bus IEP system (Shen Kuo vessel as example)

Side

propulsion

AC-DC DC-AC Side Propulsion Tx

Switchboard

(8) $\stackrel{M}{\sim}$ $2-\stackrel{M}{\sim}$

Main propulsion

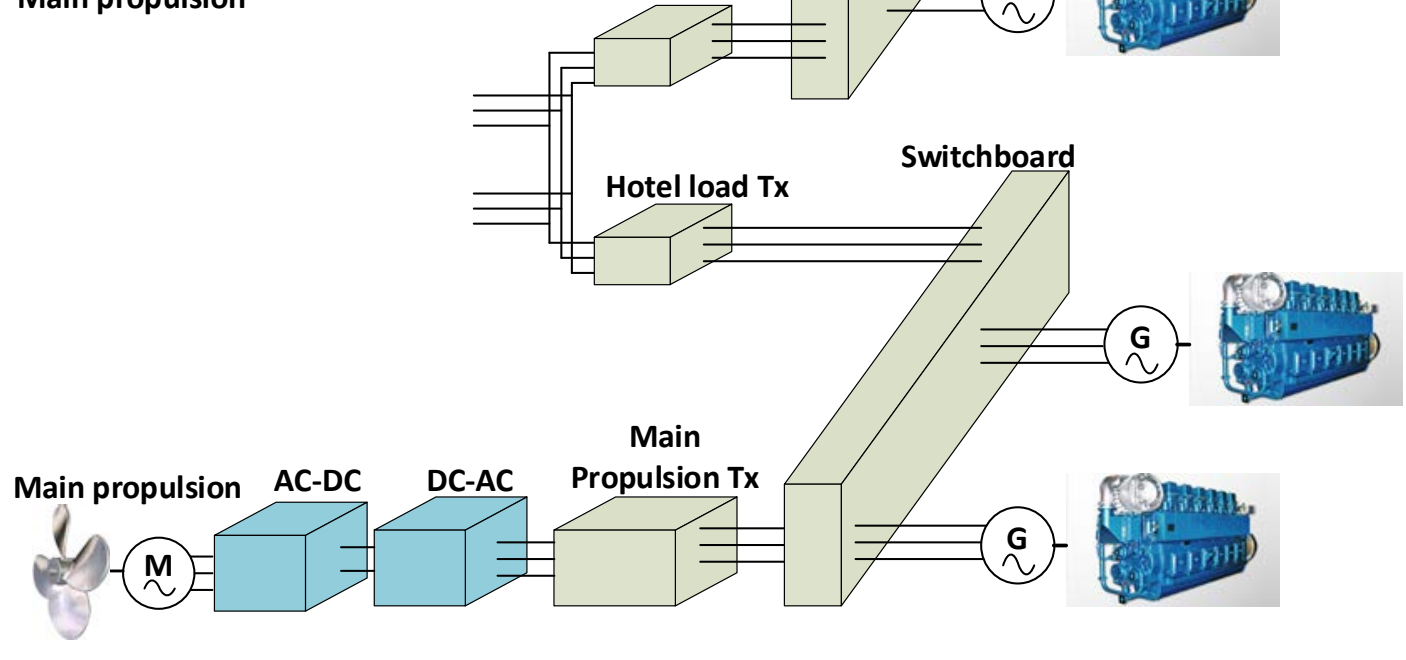

\section{Bus IEP system (Shen Kuo vessel as example)}

Integrated DC Bus and converters

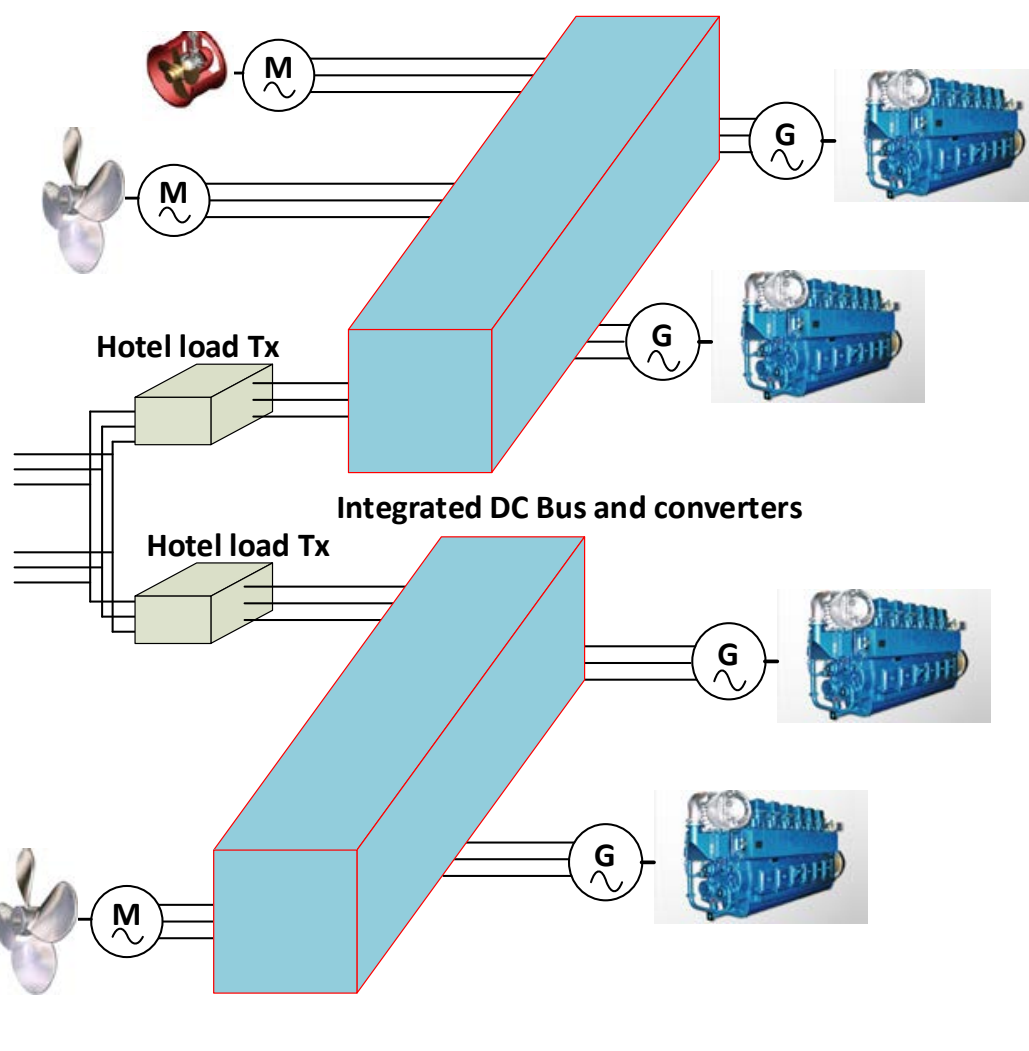

Figure 10 Comparison of system schematics between AC Bus and DC Bus IEP systems 


\subsection{Performance of a real mission}

For Shen Kuo vessel, the Cruising mode means the total power required by propulsion motors is more than $1 \mathrm{MW}$ thus each DG in the vessel needs to generate more than $50 \%$ of its rated power. When the main propulsion motors are lightly used for the Maneuver and Dynamic Positioning (DP) modes or in idle for the Docking mode, the DGs are lightly operated at less than $50 \%$ of the rated output. The advantage of DC Bus system in fuel saving and emission reduction is mainly evidenced in partial and light loading conditions of DGs.

A mission from the Southeast China coast to Mariana Trench was conducted by the Shen Kuo vessel from 17 Nov 2018 to 8 Jan 2019 and the course is shown in Figure 11. Within this 53 days' voyage, the Shen Kuo vessel had only about $20 \%$ of operation in Cruising mode and the rest is in Maneuver, DP and Docking modes as shown in Figure 12, which is a typical profile for research, engineering, and service vessels. Fuel consumption and saving breakdown at different operation modes for this specific mission is shown in Figure 13. Compared with the AC Bus system, an average of $6 \%$ fuel saving has been achieved throughout the entire mission. Albeit negligible fuel saving from Cruising mode, more than $5 \%, 6 \%$ and 9\% fuel consumption reduction has been achieved in Maneuver, DP and Docking modes, respectively. The significant fuel saving from Maneuver, DP and Docking operation modes have shown high suitability of DC Bus IEP systems for research, service and engineering ships used for more versatile duties and ferries used for short distances with frequent docking and undocking events. 


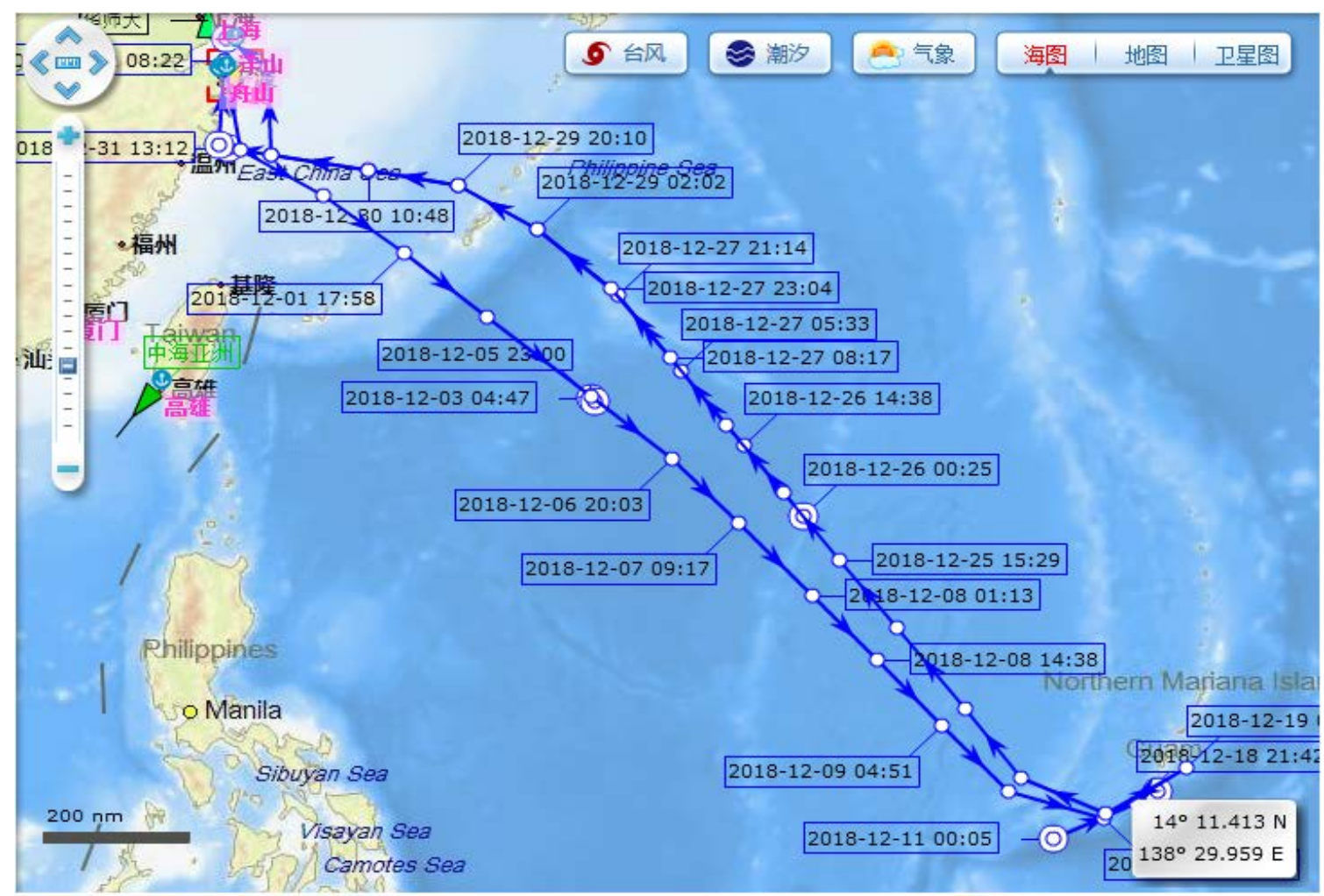

(a)

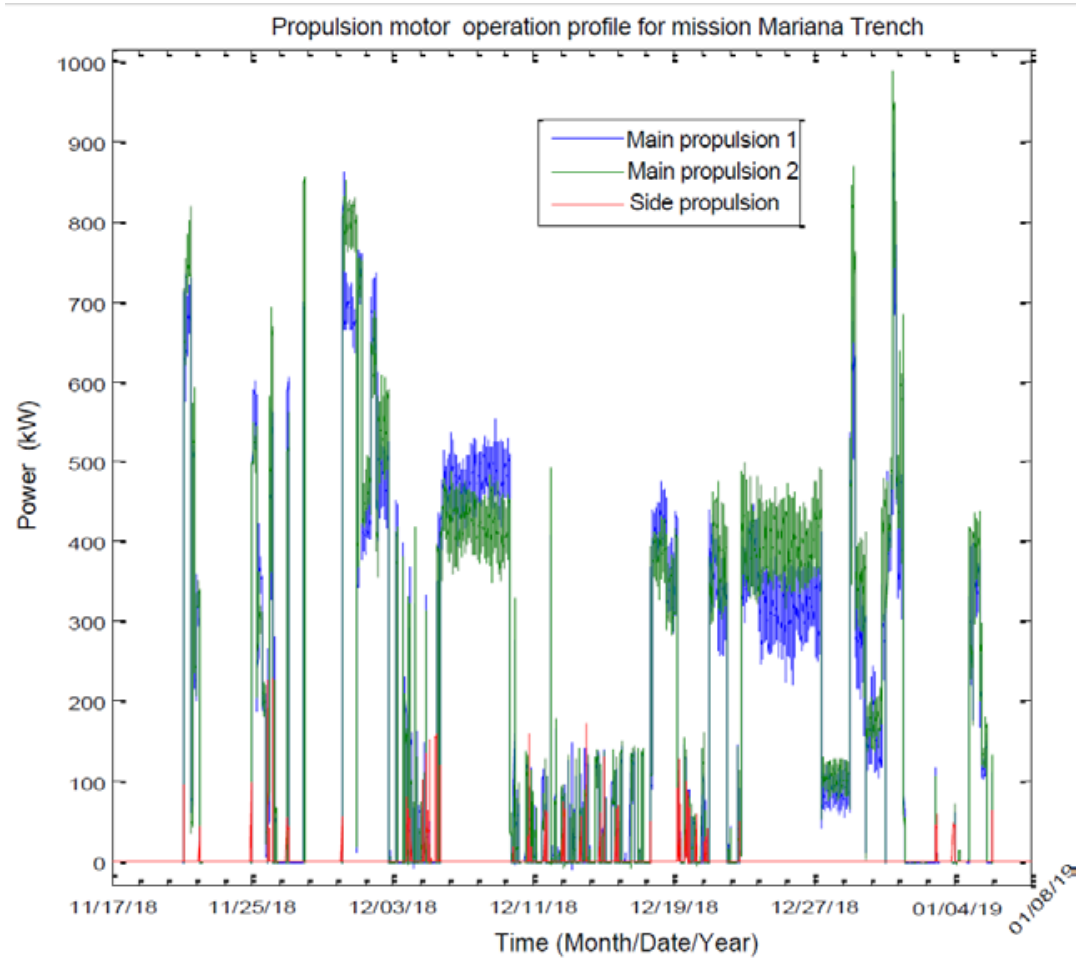

(b)

Figure 11 A mission of Shen Kuo research vessel to Mariana Trench. (a): the course; (b) operation of propulsion motors 


\section{Operation mode of Shen Kuo}

in a mission to Mariana Trench

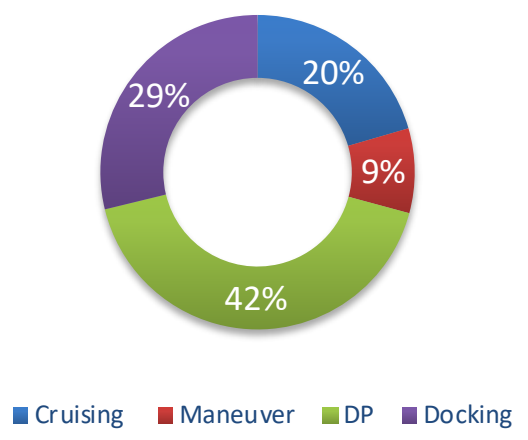

Figure 12 Operation modes of Shen Kuo research vessel in a mission to Mariana Trench

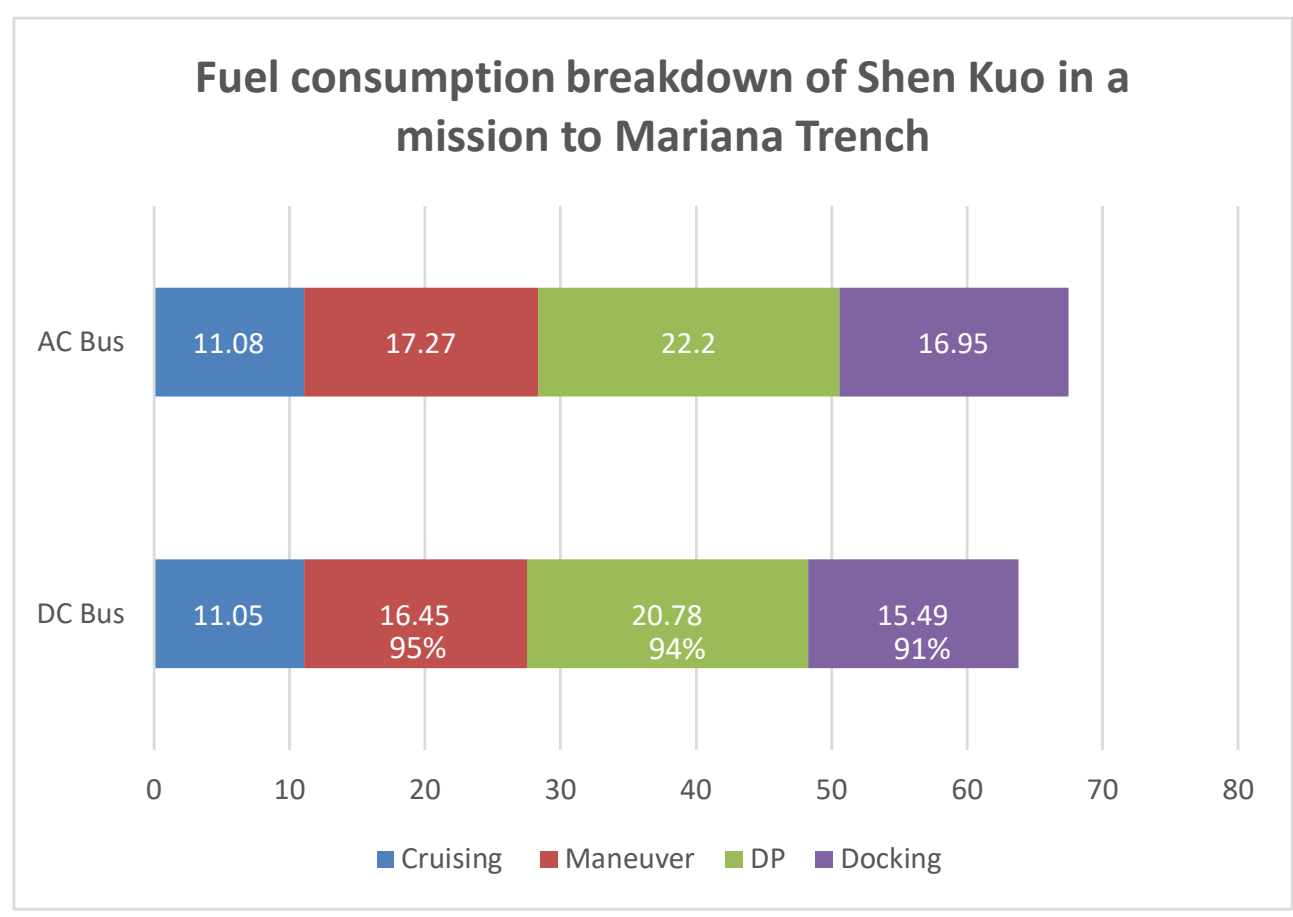

Figure 13 Fuel consumption and saving breakdown of Shen Kuo in a mission to Mariana Trench. Unit: ton (1,000 $\mathrm{kg})$

\section{Technology acceptance by the China Classification Society (CCS)}

The China Classification Society (CCS), which provides classification services to ships in accordance with international conventions and the related rules and regulations, is technically involved in promoting DC Bus IEP systems. The main challenge of the CCS certifying the DC Bus system is its protection behaviour of the DC bus short circuit. For example, calculation of different types of DC bus systems, selection of parameters for components of simulation modelling, and selective overcurrent protection for DC electrical systems. Considering the fact that the ship owners and operators are reluctant to perform 
the destructive short-circuit test on board, the CCS has proposed an innovative method by using comprehensive software simulation and full power off-land test validation to assess and approve the short circuit protection of DC Bus systems.

The CCS has produced the draft of the 'Guidelines for the DC bus system' to standardize the approval method. Moreover, due to its high technical compatibility with the energy storage system (ESS) such as batteries and super capacitors, the DC Bus system has been regarded as a promising technical candidate in vessels equipped with the ESS, and has been accepted as one of the standard topologies in the published 'Guidelines for the Hybrid-Powered Ships' in 2018 and 'Guidelines for the Pure BatteryPowered Ships' in 2019 by the CCS.

\section{Further reading}

Tae-Hwan Joung, Seong-Gil Kang, Jong-Kap Lee \& Junkeon Ahn (2020) The IMO initial strategy for reducing Greenhouse Gas(GHG) emissions, and its follow-up actions towards 2050, Journal of International Maritime Safety, Environmental Affairs, and Shipping, 4:1, 1-7

Maritime 2050: navigating the future, Department of Transport, UK Government, 2019, https://www.gov.uk/government/publications/maritime-2050-navigating-the-future

Z. Jin, G. Sulligoi, R. Cuzner, L. Meng, J. C. Vasquez and J. M. Guerrero, "Next-Generation Shipboard DC Power System: Introduction Smart Grid and dc Microgrid Technologies into Maritime Electrical Netowrks," in IEEE Electrification Magazine, vol. 4, no. 2, pp. 45-57, June 2016.

O. Alnes, S. Eriksen and B. Vartdal, "Battery-Powered Ships: A Class Society Perspective," in IEEE Electrification Magazine, vol. 5, no. 3, pp. 10-21, Sept. 2017.

A. Riccobono et al., "Stability of Shipboard DC Power Distribution: Online Impedance-Based Systems Methods," in IEEE Electrification Magazine, vol. 5, no. 3, pp. 55-67, Sept. 2017.

N. Doerry, "Naval Power Systems: Integrated power systems for the continuity of the electrical power supply.," in IEEE Electrification Magazine, vol. 3, no. 2, pp. 12-21, June 2015.

Guomei Chang (changguomei@csic-cse.com) is with the Wuxi Silent Electric Ship Technology Ltd, China Yunxiang Wu (wuyunxiang@csic-cse.com) is with the Wuxi Silent Electric Ship Technology Ltd, China Shiyi Shao (shaoshiyi@csic-cse.com) is with the Wuxi Silent Electric Ship Technology Ltd, China Zhaoxia Huang (huangzhaoxia@ccs.org.cn) is with the China Classification Society, Wuhan Rules \& Research Institute, China

Teng Long, corresponding author, (TL322@cam.ac.uk) is with the University of Cambridge, United Kingdom 